\title{
Improving Patient Dining Satisfaction: Positively Changing the Perception of Hospital Food
}

\author{
Brielle Perl ${ }^{1}$, Jill Smith ${ }^{1}$, Dahlia Abou El Hassan ${ }^{1}$ \\ ${ }^{1}$ Compass Group Canada, Mississauga, ON
}

\section{PURPOSE:}

Implement a new food service dining model for long-stay patients in the acute care environment with a variety of quality nutritional and delicious choices that enhance the patient dining experience.
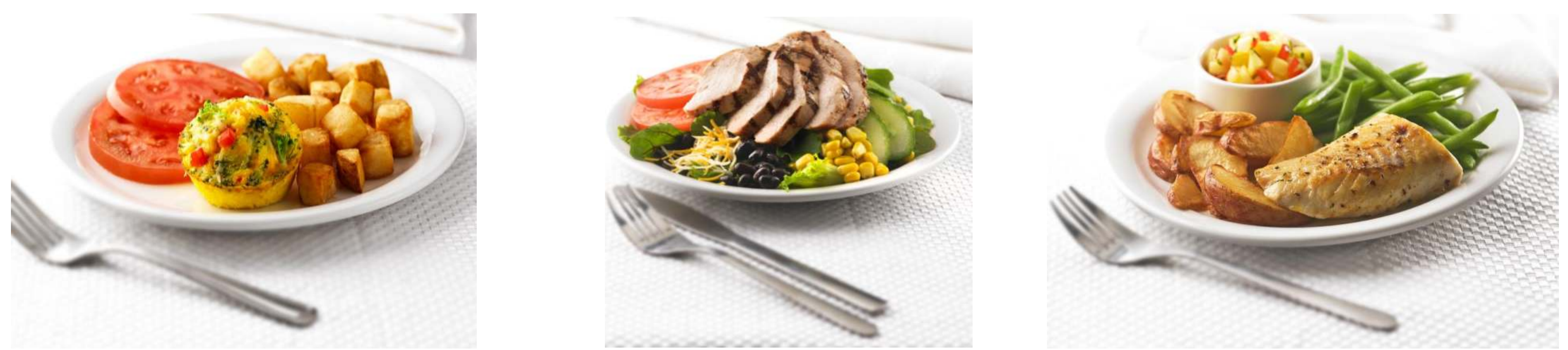

\section{SYSTEMATIC APPROACH USED:}

The new food service model was implemented $(n=100)$ with patients on rehabilitation units at an acute care facility in Burlington, ON. Pre and post tray waste audits and patient satisfaction surveys were conducted with patients to evaluate current baseline status of the patient dining experience to compare to the new model. Baseline model was a one week menu cycle, fresh steam-cooked food system with same day bedside meal selections. The new model incorporates a variety driven two week menu cycle, cook serve method with same day bedside meal selections.

\section{RESULTS:}

- Overall Patient Dining Meal Experience increased by $16 \%$

- Rating of Breakfast Taste/Flavour increased by $30 \%$

- Rating of Lunch Taste/Flavour increased by $41 \%$

- Rating of Dinner Taste/Flavour increased by $44 \%$

- Average Daily Tray Waste decreased by $15 \%$

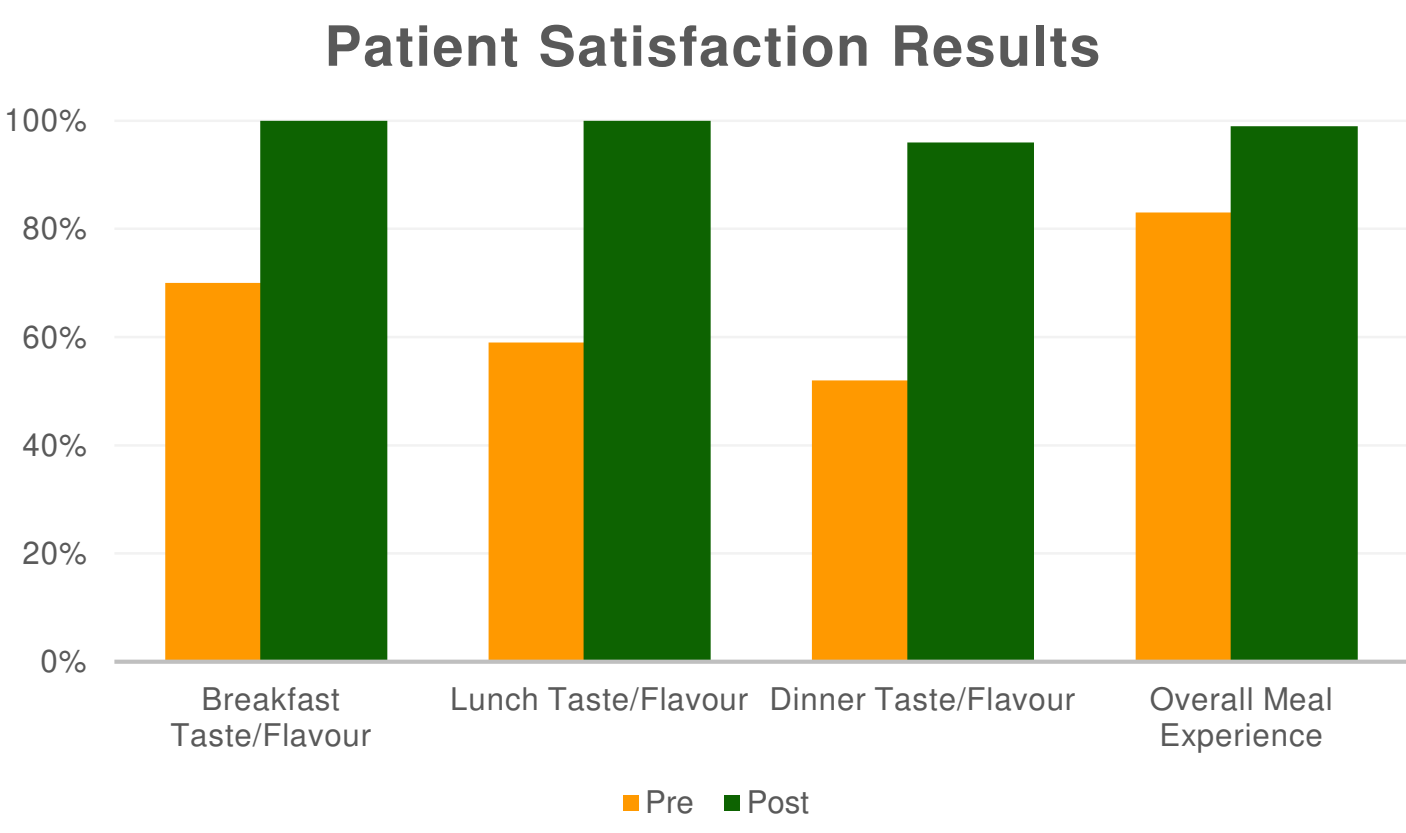

SIGNIFICANCE:

Since seeing an increase in the average length of stay in the acute care environment this program is for these patients with the goal of creating delicious, home-made food to stimulate their appetites, increase their food intake and overall dining satisfaction. This offering assists in eliminating the opportunity for menu-fatigue for longstay patients (greater than 14 days) and allows for a greater variety of meal choices. Examples of menu choices are as follows: homemade pizza, hand crafted hamburgers, lasagna and fresh fruit and vegetables thus providing patients with comforting and familiar flavours that take patients away to a place where they find solace - their home, their favorite restaurant or dining with friends.

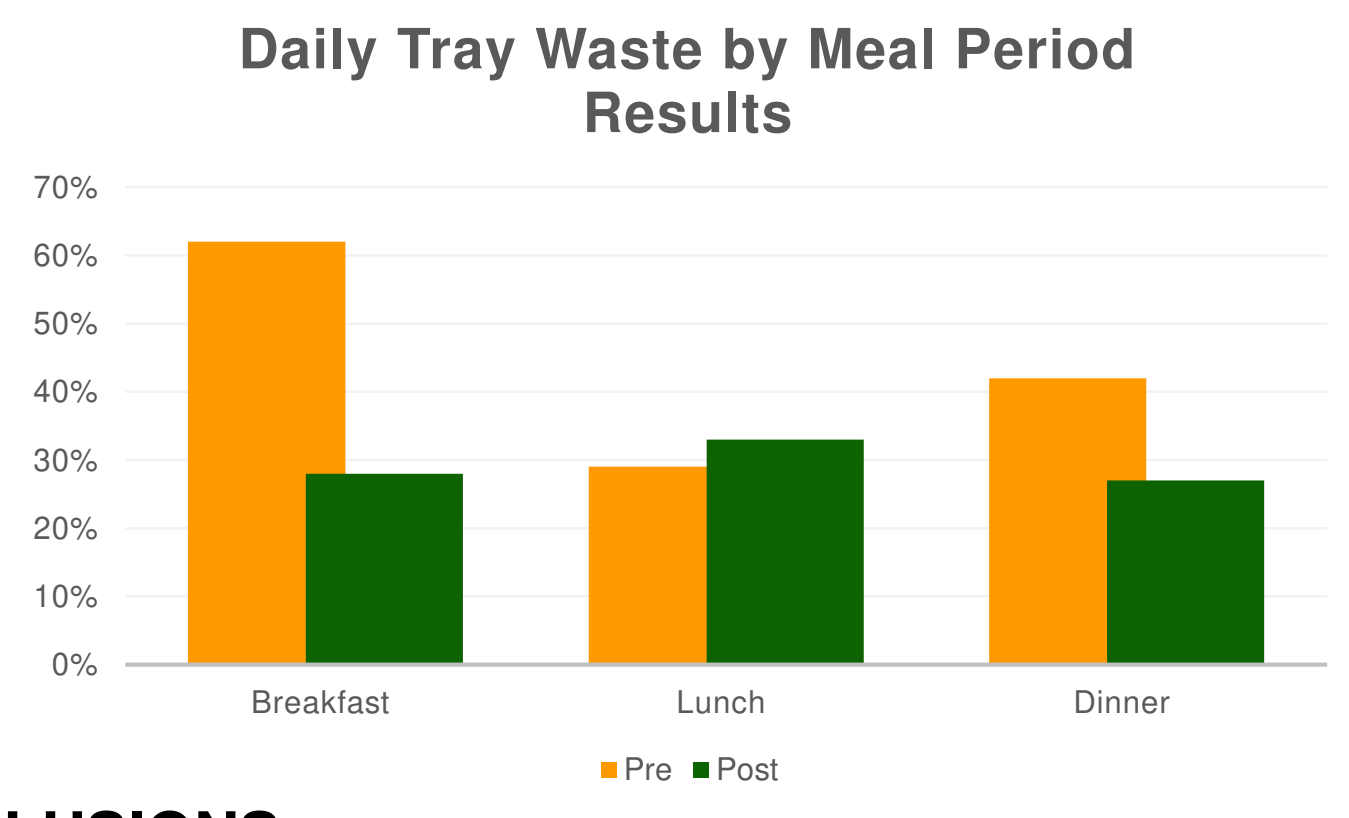

\section{CONCLUSIONS:}

The performance measurements reflect that the new food service model is successful. It enhances the patient dining experience through increasing patient satisfaction and overall consumption of meals as evidenced by increased satisfaction score results and decreased overall daily tray waste.

\section{RECOMMENDATIONS:}

To improve patient meal consumption, decrease waste and improve patient meal dining satisfaction:

- Provide default menu cycle longer than one week

- Provide a variety of flavourful choices with meal selections as close as possible to meal times

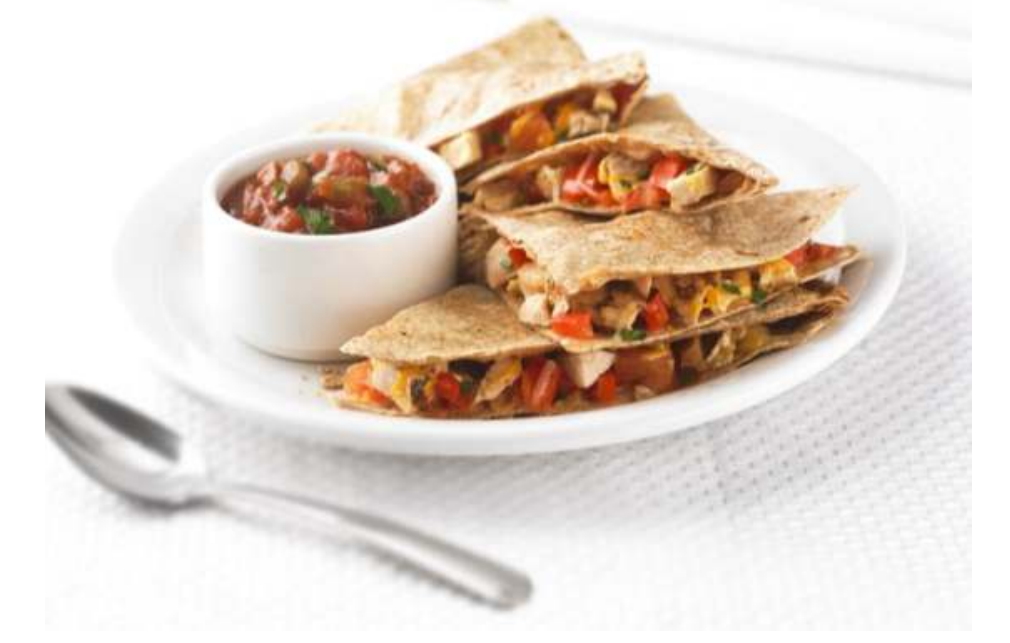

